\title{
Oral Health Access and Early Caries in Childhood in a Primary Care Service in Southern Brazil: A Cross-Sectional Study
}

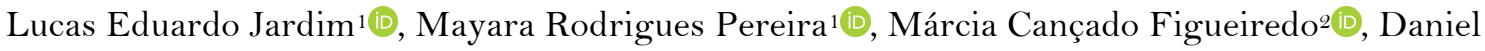 \\ Demétrio Faustino-Silva ${ }^{3}$ (D)
}

\begin{abstract}
${ }^{1}$ Integrated Residency in Healthcare, Grupo Hospitalar Conceição, Porto Alegre, RS, Brazil.
${ }^{2}$ Department of Pediatric Dentistry, School of Dentistry, Federal University of Rio Grande do Sul, Porto Alegre, RS, Brazil.

${ }_{3}^{3}$ Professional Master's Degree, Grupo Hospitalar Conceição, Porto Alegre, RS, Brazil.
\end{abstract}

Author to whom correspondence should be addressed: Daniel Demétrio Faustino-Silva, Grupo Hospitalar Conceição, Gerência de Ensino e Pesquisa, Av. Francisco Trein, 596, $3^{\circ}$ andar, Bloco H, sala 11, Porto Alegre, RS, Brazil. $91350-200$. Phone: +55513357-2407. E-mail: ddemetrio@gmail.com.

Academic Editors: Alessandro Leite Cavalcanti and Wilton Wilney Nascimento Padilha

Received: 08 June 2019 / Accepted: 14 January 2020 / Published: 10 February 2020

How to cite this article: Jardim LE, Pereira MR, Figueiredo MC, Faustino-Silva DD. Oral health access and early caries in childhood in a primary care service in southern Brazil: a cross-sectional study. Pesqui Bras Odontopediatria Clín Integr. 2020; 20:e4806. https://doi.org/10.1590/pboci.2020.033

\begin{abstract}
Objective: To evaluate the prevalence of early childhood caries and its association with Child's Programmatic Action dental visits in a Primary Care Service. Material and Methods: A cross-sectional analytical study was carried out at the Health Centers of the Grupo HospitalarConceição Community Health Service in Porto Alegre, RS, Brazil. Mothers answered a questionnaire containing socioeconomic data, eating habits and oral care of their children. Caries examination was performed by two examiners calibrated using WHO criteria. Results: Eighty-one children with mean age of 58.8 ( $\mathrm{SD}=4.8)$ months were evaluated, $58 \%$ were male. Caries prevalence was $43 \%$, with mean $\mathrm{dmft}=1.7$ and mean $\mathrm{dmfs}=3.09$. In the multivariate analysis, there was a statistically significant association of caries with maternal schooling $(\mathrm{PR}=1.31,95 \% \mathrm{CI}=1.06-1.62, \mathrm{p}=0.012)$, family income $(\mathrm{PR}=0.93,95 \% \mathrm{CI}=0.90-0.97, \mathrm{p}<0.001)$, adequacy of the number of childcare visits $(\mathrm{PR}=0.68,95 \% \mathrm{CI}=0.54-0.86, \mathrm{p}=0.001)$ and number of visits to the dentist $(\mathrm{PR}=1.04,95 \% \mathrm{CI}=1.01-1.06, \mathrm{p}=0.001)$. Conclusion: Ensuring access to childcare and early dental consultation, while the family context is disregarded, does not seem to be enough to reduce caries. It is necessary to think of non-conventional oral health promotion strategies in Primary Health Care taking into account the territory and social determinants since changes to eating and oral hygiene habits and behaviors are still a challenge to the control of childhood caries.
\end{abstract}

Keywords: Dental Caries; Child; Primary Health Care; Health Services Accessibility; Oral Health. 


\section{Introduction}

Early Childhood Caries (ECC) is given this designation because it affects children under age six, and when it affects those under age three, it is called Severe Early Childhood Caries (SECC) [1]. When affecting this age group, the disease manifests itself aggressively, causing the mutilation of children by destroying completely and quickly their teeth, resulting in discomfort, pain, infection, and abscesses; a clinical condition that can impair healthy growth, development and quality of life. By mutilating children, ECC hinders adequate nutrition and obtaining of nutrients and has the potential to lead to malnutrition and consequent delay of growth, cognitive, behavioral development and quality life, in addition to aesthetic impairment that causes low self-esteem and relationship problems [2].

According to the results of the Brazilian oral health survey performed by the Brazilian Ministry of Health [3], about 27\% of children aged 18-36 months have at least one deciduous tooth with dental caries, and the proportion reaches almost $60 \%$ of five-year-old children [3]. In the Brazilian epidemiological survey of 2010 , in which only the 5-year age group was evaluated, there was a slight reduction in caries prevalence $(53 \%)$ with a mean dmft of 2.43 , and the decayed component accounted for $80 \%$ [4]. The numbers indicate that early childhood caries prevention and treatment is still necessary.

Although authors assert that caries prevalence has tended to decline in the past decades, inequalities can be seen in oral health [5]. Furthermore, this condition has been described as one of the major challenges to be faced in terms of public health [6,7]. At national level, despite the aforementioned decline that has also been observed worldwide, dental caries remains the main oral health problem to be addressed, including children and adolescents [8]. Despite the efforts to control the disease at the global level, the percentage of untreated cavity is still high, and the reparation of its sequels generates significant economic impact [9,10].

Early childhood is the ideal time to introduce good habits and initiate an educational/preventive oral health program. However, it is important to count on the active participation of the family and Health Teams, since oral health is an inseparable part of general health. As a way of coping with health problems and conditions subject to Primary Health Care (PHC), such as Early Childhood Caries, the Brazilian Ministry of Health, which manages the Unified Health System (SUS), has in the Family Health Strategy (ESF) its main tool to act within a territory, aiming at each family and individual, and the Family Health Team is responsible for promoting health, prevention, treatment and rehabilitation.

According to the Primary Care Book No. 17-Oral Health of the Ministry of Health [11], the previous stages of ECC, before cavitation, can be thwarted by health promotion and preventive actions. Working from this perspective, the Grupo Hospitalar Conceição (SSC-GHC) Community Health Service, basing its practices on the principles of SUS and Primary Health Care, initially included oral health in the Child's Programmatic Action in 2009 as a prototype. However, in 2010, it was added to health indicators and became one of the targets of the service. This Action supports annual dental visits starting in the first year of the child's life using the cohort born in 2010 with the aim of guiding caregivers about the importance of food, oral hygiene and other healthy habits, besides behaviors related to the oral health of the child.

The hypothesis of the study is that children monitored by a programmatic and systematized action in a health service should have lower caries rates. However, little is known about the benefits of these preventive programs and their impact on the reduction of ECC in the population. In order to qualify the strategies of oral health care in the PHC/SUS using a scientific basis, it is necessary to evaluate the effectiveness of these programmatic actions. Therefore, this is a pioneering study aiming to evaluate caries prevalence and the 
association with the follow-up and coverage of dental visits under the Child's Programmatic Action program in two SSC-GHC Health Centers (HC) in the city of Porto Alegre, Brazil.

\section{Material and Methods}

Study Design and Participants

This is a cross-sectional study that evaluated children born in 2010 who were monitored by the Oral Health Team in two Health Centers (HC) of the Grupo Hospitalar Conceição Community Health Service (SSCGHC) in the city of Porto Alegre/RS, Brazil, between March and June 2015.

The GHC is a health service network made up of four hospitals: Hospital Conceição, Hospital da CriançaConceição, Hospital Cristo Redentor, Hospital Fêmina and Community Health Service (SSC). The SSCGHC is linked to the Ministry of Health and responsible for health care in the northern area of the city of Porto Alegre - Rio Grande do Sul, Brazil. The SSC/GHC is a Primary Health Care service comprised of 12 health centers including professionals from the minimum Family Health team (Family Physicians, Dentists, Oral Health Technicians, Nurses, Technicians, and Nursing Assistants) and professionals from the Family Health Support Center (Social Assistants, Psychologists, Nutritionists, and Pharmacists), who provide care to approximately 105,000 registered people. In 2010, the SSC included oral health in the Child's Programmatic Action program in order to guarantee access to dental visits for children from the first year of life and provide preventive advice to mothers, fathers or caregivers focusing on early childhood caries prevention and guided by a service protocol [12,13].

Four-year-old children born in 2010 and enrolled in the Children's Program in the area covered by the two SSC-GHC health centers were included in the study. Children who, even if born in 2010, did not remain, for any reason, in the Children's Program in the area covered by the two SSC-GHC centers were excluded, as well as children who did not allow the oral examination to be performed, as described in Figure 1. Since this was an exploratory study and there were no previous studies with this approach in the literature, it was not possible to estimate the sample and, therefore, 81 children from the two centers were evaluated. The power of the sample was calculated using the PEPI program, version 4 (Computer Programs for Epidemiologists), for a significance level of $5 \%$, considering the variables caries presence and number of visits to the dentist. The difference in the average number of visits to the dentist (1.62) between the groups with (5.09 \pm 3.58$)$ and without caries $(3.47 \pm 1.91)$ was used. The power obtained was $73.23 \%$.

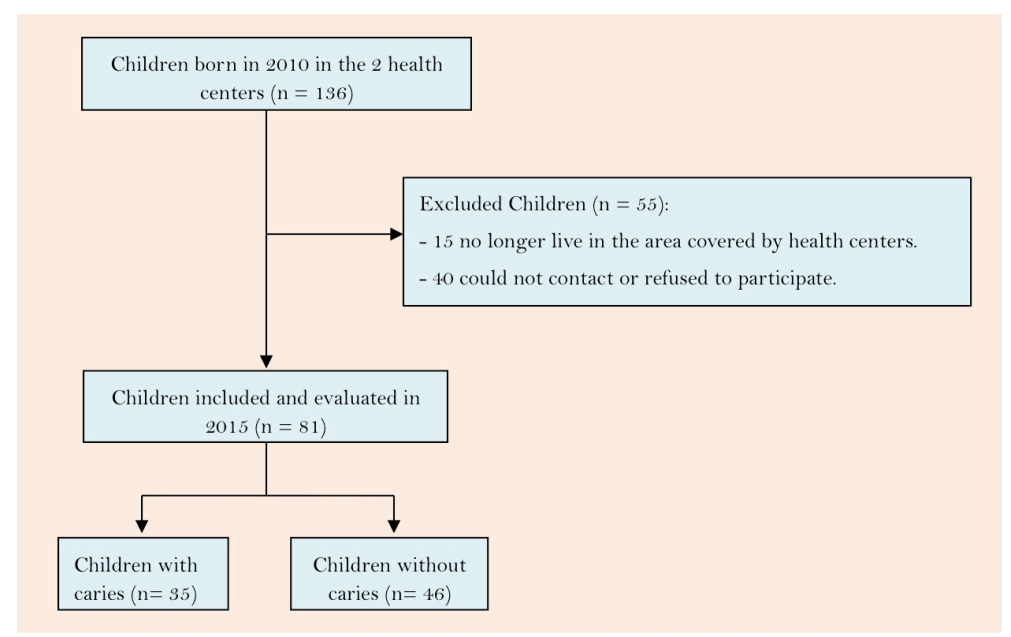

Figure 1. Flowchart of the study population. 


\section{Procedures and Data Collection Instruments}

Prior to data collection, the investigators, one dentist from each center, were trained and calibrated for caries diagnosis. The $\mathrm{dmft} / \mathrm{dmfs}$ index recommended by the World Health Organization was used. The index represents a summation of decayed teeth or dental surfaces, filled or with indication of extraction, with $\mathrm{dmft} / \mathrm{dmfs}>\mathrm{o}$ indicating the presence of caries. The calibration of the two examiners was performed in two steps, with a weekly interval, using exfoliated and/or extracted teeth according to the methodology described previously, used and validated by other studies [14,15]. The calibration results were analyzed using the weighted Kappa coefficient, of which the mean intra-examiner and inter-examiner values were 0.79 and 0.75. The two examiners were also trained for completing forms and questionnaires.

The guardians of the children were invited to participate in the study by means of appointments in the health centers and home visits. Prior to the interview, the purposes of the study were presented on an Informed Consent Form, which was read and signed. Subsequently, a questionnaire containing data on socioeconomic conditions, eating and oral hygiene habits and access to oral health services was completed. Data regarding dental appointments were collected from the SSC-GHC Information System and Annual Monitoring and Evaluation Reports. The examinations were carried out under natural light, with the aid of wooden spatulas for separation and removal of possible debris on dental surfaces, and, where necessary, gauze was used.

\section{Statistical Analysis}

The data were analyzed using the Chi-square test and Poisson regression with robust variance. All variables associated with the caries outcome, with a p-value $<0.20$, were considered potential confounders and included in the multivariate model. Variables with a p-value $<0.05$ were considered statistically significant. The SPSS software version 16.0 (SPSS Inc, Chicago, IL, USA) and Stata v 11.0 software (StataCorp, College Station, Texas, USA) were used.

Ethical Aspects

The project was previously approved by the Research Ethics Committee of Grupo Hospitalar Conceição, registered in the Brazil Platform under CAAE No. 38414614.4.00005530, complying with the norms of the Brazilian National Health Council Resolution No. 466/12.

\section{Results}

Table 1 outlines the socioeconomic profile, health status, habits and the follow-up of children, correlating the variables with the caries (presence or absence) outcome. Caries prevalence was 43\%, with mean $\mathrm{dmft}=1.7$ and mean $\mathrm{dmfs}=3.09$. Of the 81 children in the sample, most were males and with mean age of 58 months. There was no statistical difference in caries prevalence between boys and girls $(\mathrm{p}=0.75)$. With respect to ethnicity, $62.9 \%$ children were white and most showed a dmft index equal to zero compared to non-white $(\mathrm{p}=0.02)($ Table 1$)$.

With respect to the parents, the mothers of children with $\mathrm{dmft}>0$ had a mean age in years of $32.54( \pm$ $11.24)$ versus $33.76( \pm 8.24)$ for the mothers whose children had $\mathrm{dmft}=0(\mathrm{p}=0.61)$. The mothers who did not complete high school accounted for $64.1 \%$ of the children with caries in the sample, while the mothers with full secondary education or more years of schooling accounted for $24.4 \%$ of the children with positive dmft, a statistically significant finding $(\mathrm{p}<0.01)$. Of the mothers whose children presented with caries disease, $44.4 \%$ had dental appointments during pregnancy, while $47.1 \%$ did not have $(p=0.84)$ (Table 1$)$. 
Table 1. Characteristics of children regarding the Early Childhood Caries outcome.

\begin{tabular}{|c|c|c|c|}
\hline Variables & $\begin{array}{c}\text { dmft }>0 \\
N(\%)\end{array}$ & $\begin{array}{c}\mathbf{d m f t}=\mathbf{0} \\
\mathrm{N}(\%)\end{array}$ & p-value \\
\hline Age in Months (Mean $\pm \mathrm{SD})$ & $58.71( \pm 4.86)$ & $58.87( \pm 4.76)$ & 0.88 \\
\hline \multicolumn{4}{|l|}{ Sex } \\
\hline Male & $21(44.7)$ & $26(55.3)$ & 0.75 \\
\hline Female & $14(41.2)$ & $20(58.8)$ & \\
\hline \multicolumn{4}{|l|}{ Ethnicity } \\
\hline White & $17(33.3)$ & $34(66.7)$ & 0.02 \\
\hline Non-white & $18(60.0)$ & $12(40.0)$ & \\
\hline \multicolumn{4}{|l|}{ Day Care Center Attendance } \\
\hline Yes & $22(37.3)$ & $37(62.7)$ & 0.05 \\
\hline No & $13(61.9)$ & $8(38.1)$ & \\
\hline \multicolumn{4}{|l|}{ Help with Care } \\
\hline Father/Mother & $10(71.4)$ & $4(28.6)$ & 0.06 \\
\hline Siblings & $12(31.6)$ & $26(68.4)$ & \\
\hline Others & $2(66.7)$ & $1(33.3)$ & \\
\hline Nobody & $11(42.3)$ & $15(57.7)$ & \\
\hline Mother's Age in Years (Mean $\pm \mathrm{SD}$ ) & $32.54( \pm 11.24)$ & $33.76( \pm 8.24)$ & 0.61 \\
\hline \multicolumn{4}{|l|}{ Mother's Schooling } \\
\hline Up to Incomplete High School & $25(64.1)$ & $14(35.9)$ & $<0.01$ \\
\hline Complete High School or More & $10(24.4)$ & $31(75.6)$ & \\
\hline \multicolumn{4}{|l|}{ Mother's Occupation } \\
\hline Does not Work Out & $12(54.5)$ & $10(45.5)$ & 0.17 \\
\hline Medium Level Job of Different Kinds & $22(42.3)$ & $30(57.7)$ & \\
\hline Higher Level Job & $1(14.3)$ & $6(85.7)$ & \\
\hline \multicolumn{4}{|l|}{ Pregnant Woman's Visit } \\
\hline Yes & $12(44.4)$ & $15(55.6)$ & 0.84 \\
\hline No & $16(47.1)$ & $18(52.9)$ & \\
\hline Household Size & $4.2( \pm 1.53)$ & $3.8( \pm 1.09)$ & 0.15 \\
\hline Gross Income in Minimum Wages & $1.94( \pm 0.90)$ & $3.15( \pm 2.40)$ & $<0.01$ \\
\hline Per Capita Income in Brazilian Real & $391.22( \pm 186.92)$ & $512.67( \pm 462.26)$ & $<0.01$ \\
\hline \multicolumn{4}{|l|}{ Bolsa Família Program } \\
\hline Yes/Had Previously & $16(57.1)$ & $12(42.9)$ & 0.07 \\
\hline No & $19(36.5)$ & $33(63.5)$ & \\
\hline \multicolumn{4}{|l|}{ Type of Housing } \\
\hline Wood/Mixed & $12(66.7)$ & $6(33.3)$ & 0.02 \\
\hline Brick & $23(36.5)$ & $40(63.5)$ & \\
\hline \multicolumn{4}{|l|}{ Type of Tooth Paste } \\
\hline Without Fluorine/Does Not Use & $1(50.0)$ & $1(50.0)$ & 0.49 \\
\hline 500ppm & $4(28.6)$ & $10(71.4)$ & \\
\hline $1100 p p m$ & $28(45.9)$ & $33(54.1)$ & \\
\hline \multicolumn{4}{|l|}{ Oral Hygiene Instrument } \\
\hline Children's Toothbrush & $28(38.4)$ & $45(61.6)$ & $<0.01$ \\
\hline Adult Toothbrush & $7(87.5)$ & $1(12.5)$ & \\
\hline \multicolumn{4}{|l|}{ Oral Hygiene Receptivity } \\
\hline Receptive & $24(38.1)$ & $39(61.9)$ & 0.08 \\
\hline Non-receptive & $7(77.8)$ & $2(22.2)$ & \\
\hline Variable & $4(44.4)$ & $5(55.6)$ & \\
\hline \multicolumn{4}{|l|}{ Pacifier } \\
\hline Yes & $10(55.6)$ & $8(44.4)$ & 0.23 \\
\hline No & $25(39.7)$ & $38(60.3)$ & \\
\hline Frequency of Sugary Liquids (Times per Week) & $2.91( \pm 0.37)$ & $2.61( \pm 0.80)$ & 0.10 \\
\hline
\end{tabular}




\begin{tabular}{|c|c|c|c|}
\hline \multicolumn{4}{|l|}{ Sugary Liquid Period } \\
\hline Day & $7(28.0)$ & $18(72.0)$ & 0.16 \\
\hline Night & $3(50.0)$ & $3(50.0)$ & \\
\hline Day/Night & $25(51.0)$ & $24(49.0)$ & \\
\hline \multicolumn{4}{|l|}{ Childcare Visit Adequation } \\
\hline Yes & $6(75.0)$ & $2(25.0)$ & 0.06 \\
\hline No & $29(39.7)$ & $44(60.3)$ & \\
\hline \multicolumn{4}{|l|}{ Dental Treatment Adequation } \\
\hline Yes & $7(50.0)$ & $7(50.0)$ & 0.60 \\
\hline No & $28(42.4)$ & $38(57.6)$ & \\
\hline Age at First Visit to Dentist (Months) & $18.91( \pm 18.55)$ & $23.55( \pm 20.08)$ & 0.31 \\
\hline Number of Visits To Dentist ${ }^{\#}$ & $5.09( \pm 3.58)$ & $3.47( \pm 1.91)$ & $<0.01$ \\
\hline
\end{tabular}

\#Absolute number.

The mean family gross income of children with caries was $1.94( \pm 0.90)$ minimum wages, while for those free of caries, it was $3.15( \pm 2.40)(\mathrm{p}<0.01)$. Children whose families have or had Bolsa Família (family grant) accounted for $57.1 \%$ of those with positive $\mathrm{dmft}$, and those who do not receive or never received the benefit, $36.5 \%(\mathrm{p}=0.07)$ (Table 1$)$.

The type of toothpaste used by the children in the research was mostly the same as that of their relatives, that is, the toothpaste containing $1100 \mathrm{ppm}$ of fluoride, present in the oral hygiene of more than $70 \%$ of the sample. Of these 61 children, $45.9 \%$ were diagnosed with caries, while $54.1 \%$ had $\mathrm{dmft}=0(\mathrm{p}=0.49)$. The prevailing oral hygiene tool was the infant toothbrush (90.1\%) (Table 1).

As for eating habits, the children with $\mathrm{dmft}>0$ consumed sugary liquids with a mean frequency of 2.91 $( \pm 0.37)$ times per week, whereas those with $\mathrm{dmft}=\mathrm{o}$ had this frequency reduced to $2.61( \pm 0.80) \mathrm{p}=0.10$. Most children who presented with caries had greater consumption of sugary liquids during day and night, $71.4 \%$ $(\mathrm{p}=0.16)($ Table 1$)$.

Regarding the follow-up of patients in the health centers, the adequacy of childcare follow-up indicated that more than $90 \%$ of the sample did not attend the minimum number of medical and nursing consultations in the first year of life; of these, $60.3 \%$ were free of caries $(p=0.06)$. Regarding the follow-up by the dentist, the mean number of consultations of children with positive dmft was $5.09( \pm 3.58)$ and the mean number for those with dmft equal to zero was 3.47 ( \pm 1.91$)$, showing statistical significance $(\mathrm{p}<0.01)($ Table 1$)$.

Table 2 shows the variables chosen for the multivariate analysis model. Higher gross family income $(\mathrm{PR}=0.93 ; 95 \% \mathrm{CI}=0.90-0.97 ; \mathrm{p}<0.001)$ was associated with the absence of caries. Likewise, the nonadequacy of childcare consultations also showed this correlation; both according to the final multivariate analysis model $(\mathrm{PR}=0.68 ; 95 \% \mathrm{CI}=0.54-0.86 ; \mathrm{p}=0.001)$. The variables maternal education below high school $(\mathrm{PR}=1.31 ; 95 \% \mathrm{CI}=1.06-1.62 ; \mathrm{p}=0.012)$ and number of visits to the dentist $(\mathrm{PR}=1.04 ;(95 \% \mathrm{CI}=1.01-1.06)$, $\mathrm{p}=0.001)$ showed significant association with caries prevalence according to the final multivariate analysis model.

Table 2. Poisson regression analysis for Early Childhood Caries.

\begin{tabular}{lcccc}
\hline \multicolumn{1}{c}{ Variables } & Crude PR $(\mathbf{9 5} \% \mathbf{C I})$ & p-value & Adjusted PR $(\mathbf{9 5} \% \mathbf{C I})$ & p-value \\
\hline $\begin{array}{l}\text { Mother's Schooling } \\
\quad \text { Complete High School or More }\end{array}$ & 1 & & & \\
$\quad \begin{array}{l}\text { Up to Incomplete High School } \\
\text { Gross Family Income }\end{array} \quad 2.63(1.46-4.73)$ & $\mathrm{p}=0.001$ & $1.31(1.06-1.62)$ & $\mathrm{p}=0.012$ \\
$\quad$ Minimum Wages & $0.68(0.53-0.86)$ & $\mathrm{p}=0.001$ & $0.93(0.90-0.97)$ & $\mathrm{p}<0.001$
\end{tabular}


Childcare Visit Adequation

Adequate $(>7$ Visits

1

Not Adequate $(<7$ Visits

$0.53(0.32-0.86)$

$\mathrm{p}=0.011$

$0.68(0.54-0.86)$

$\mathrm{p}=0.001$

Number of Visits to Dentist

$1.09(1.04-1.13)$

$\mathrm{p}=0.000$

$1.04(1.01-1.06)$

$\mathrm{p}=0.001$

Model accuracy: Deviance (13.261); Pseudo R2 (0.0684)

\section{Discussion}

Any health promotion action or preventive program essentially need evaluation, and this is not different for oral health actions. The impact of the dentist's performance, but not only his, on oral health and his actions and the planning of strategies should not focus only on curative clinical procedures, but also and especially on preventive and promotional activities [16]. Evaluating and planning ensures the reinforcement of correct practices, a foundation for adopting new postures, new methodologies for health practice, improvements in team performance, and correction of direction, when necessary, in addition to better solutions, of course.

In this context, this study sought to identify the effectiveness of the Child's Programmatic Action, evaluating, for this purpose, the prevalence of dental caries in a cohort of children born in 2010 and its association with access to dental consultations in early childhood.

According to the results, the adequacy of dental consultations (one visit per year of life up to 4 years of age) did not have an impact on caries prevention $(\mathrm{p}=0.60)$. It should be emphasized that this finding reinforces the concept that dental caries, as well as early childhood caries, is a complex and multifactorial disease related to several factors, such as habits, eating patterns, education, income, housing, environment, autonomy, and access to health services. In this sense, good oral health is fundamentally linked to the improvement and addressing of social, political and economic determinants [17]. In addition, more effective approaches should be contemplated to change health-related habits and behaviors. In this sense, a cognitive-behavioral approach known as Motivational Interviewing has emerged in the literature with good results in the improvement of chronic health conditions, such as caries [18-20].

It should be noted that although the adequacy of dental consultation was not significant, it is by no means irrelevant. The child's programmatic action is a tool for health education, an important form of access and a very potent space, as its efforts focus on the importance of oral hygiene, healthy habits and eating aspects. Regarding the latter, many studies indicates that high frequency consumption, as well as the retention of sugary liquids, such as industrialized juices, sweetened teas, chocolate drinks, milk with fermentable carbohydrates and farinaceous products, for a long time in the oral environment as factors strongly related to early childhood caries. Similarly, studies show that the increased intake of fermentable carbohydrates established from birth to the first two years of life often remains in early childhood until the first five years, being associated with caries prevalence [2,7,21].

It is necessary to reiterate that, along with behavioral factors such as habits and feeding, there are social determinants, aspects of great relevance and strongly associated in the etiopathogenesis of dental caries and early childhood caries. According to this survey, for the gross family income variable, considering the monthly income measured in minimum wages, as the minimum wage increases, the risk of a child having caries decreases by $21 \%(p=0.034)$. Regarding the maternal schooling variable, one year less of study represented a 2.13 (1.19-3.80) fold chance of a child presenting with caries $(\mathrm{p}=0.010)$.

The literature brings numerous reports supporting the relation between socioeconomic determinants and dental caries. A study that evaluated the influence of social determinants on caries prevalence, using the SB 
Brasil 2010 results, and underscored that the association between socioeconomic condition and caries remained even after adjusted analysis, with a significant relationship between low income, higher consumption of sugary liquids, less access to health services and poor oral hygiene pattern [22]. Such findings may indicate that the consumption of foods high in sucrose is favored by cultural issues and a lower family income, since they are cheaper, and a poor oral hygiene pattern can result from restricted access to health services and, consequently, to preventive actions and promotion of healthy habits.

Other studies analyzed preschoolers and schoolchildren [23,24]. Only the former had dental examinations (dmft criteria); however, both administered questionnaires to parents/guardians considering socioeconomic data and highlighting information on family income and maternal schooling. According to the results of these studies, there is strong association between low social status, lower level of maternal education and high caries prevalence.

Lower income and low schooling are closely related factors [25,26]. Fewer years of study by the mother imply less information, less understanding of risks (probably less demand for health services, as there is less understanding of real needs) and difficulty developing autonomy, taking care of one's own health and ceasing harmful habits.

Albeit crucial, cessation of unhealthy habits is complex. This is a process that evolves over time, necessarily involving co-responsibility between the healthcare provider and the service user. A report of an experience [27] brings a model of joint consultation between nutritionists and dentists where a treatment was developed addressing issues such as healthy eating, oral hygiene habits, control of sucrose intake and adequate use of fluorine with parents and guardians. In the above health education experience, in addition to significant absenteeism, it was found that some parents usually did not feel responsible for oral hygiene care and eating habits, delegating this responsibility to healthcare providers. It was also observed in the study above, as well as in other studies, that a large number of mothers did not adhere to the guidelines, intentionally or unintentionally, forgetting, ignoring or executing erroneously the treatment and self-care recommendations, leading to the belief that the information was conveyed in an incomprehensible / incorrect way or that familial and/or cultural variables had greater influence on the outcome.

In this study, issues that are similar in nature to those described above may have influenced the nonsignificance of the adequacy of dental visits to reduce the prevalence of early childhood caries under the Child's Programmatic Action program. Changing habits also requires time, in addition to many other factors. The cohort of children born in 2010 probably needs to be monitored, together with their parents, for more years.

Another determining factor is the activity of Dentistry and how this is viewed. Dental practice is still regarded as something very little preventive and health promoting, being essentially curative and restorative, and requiring little multi professional activity. This is often the real situation. A large part of health service users seek dental care only in case of pain or aesthetic need. This fact was evidenced by the finding that at each additional dental appointment, the chance of the child presenting with caries increased by 1.04 (1.01-1.06) times $(p=0.001)$; corroborating the idea that the larger number of consultations was due to care restoration treatment instead of prevention.

Studies have reinforced the idea that dental training in the university privileges the curative paradigm, which is the philosophy that guides universities, whose education is not oriented by the epidemiological, social, cultural and economic situation of the population [28]. Other papers identify, in some places of the country, a highly technical, curative and individual-based professional attitude on the part of dentists in Primary Health Care [29]. 
The insertion of the dentist in the health team and his transdisciplinary work is also a decisive factor for the success of health education actions such as the Child's Programmatic Action. The analysis of childcare adequacy revealed that those children whose number of consultations was below the recommended ideal had $32 \%$ lower chance of developing dental caries $(\mathrm{p}=0.001)$. This finding reinforces the idea that it is not always those who access the health service the most who have better health conditions and that other social and cultural factors may be more determinant.

The continued effort of the dentist to educate other members of the health team, such as doctors and nurses, about practices and provide information on early-life oral health is necessary and may result in the integration of skills for better child health. A study [30] found that healthcare providers needed to be updated about changes related to the general health of children, since the administration of a questionnaire about earlylife oral health practices and knowledge showed that these had inadequate knowledge and procedures. Periodic actions of continuing education on oral child health should aim at the qualification and updating of professionals.

Based on the complex context involving dental caries and the practice of health providers, dentists, as well as the teams in which they are included, should change their attitudes and empower users. It is necessary to establish bonds, co-responsibility relationships, motivate and advise the patient, leaving clinical practice to the right time. New collective actions, changes, improvements, evaluations of the existing ones should be proposed, focusing on the planning of public measures for the promotion of oral health, considering the effect of contextual factors as a determinant of individual risks [22].

The Child's Programmatic Action of the Child, as a form of health education and ensuring access, is of great importance, although the adequacy of the ideal number of consultations during the first four years of children's lives was not relevant to the prevention of early caries.

Ensuring access to dental consultation and to other childcare professionals does not seem to be enough to manage early childhood caries. It is necessary to think about the type and form of approach, focusing on the multiple causes of caries and considering the socioeconomic conditions of the family. Changing self-care habits, eating patterns, oral hygiene and many other determinants, disseminating knowledge, as well as the fundamental shift from a purely curative Dentistry to one based on the precepts of health promotion and disease prevention, is a challenge that depends on the participation and co-responsibility of health providers and users, with Primary Health Care being the care level that is best suited for this practice.

Likewise, the work in face of the socioeconomic determinants of caries, which are perhaps the most significant for the development of the disease, is complex and must be constantly evaluated and discussed again, and health education actions are certainly crucial to this process.

The study's limitations include the cross-sectional analysis for which the reverse causality of associations should always be considered. In addition, a small sample of children from two health centers was evaluated, limiting the generalization of data to other populations.

Finally, the study points out the need to think of non-conventional oral health promotion strategies in Primary Health Care taking into account the territory and social determinants, since changes to eating and oral hygiene habits and behaviors are still a challenge to the control of childhood caries.

\section{Conclusion}

Ensuring access to childcare and early dental consultation, while the family context is disregarded, does not seem to be enough to reduce caries. It is necessary to think of non-conventional oral health promotion 
strategies in Primary Health Care taking into account the territory and social determinants, since changes to eating and oral hygiene habits and behaviors are still a challenge to the control of childhood caries.

\section{Acknowledgements:}

To the Grupo Hospitalar Conceição Community Health Service for supporting the study and to Vania

Naomi Hirakata for her statistical advice.

\section{Authors' Contributions}

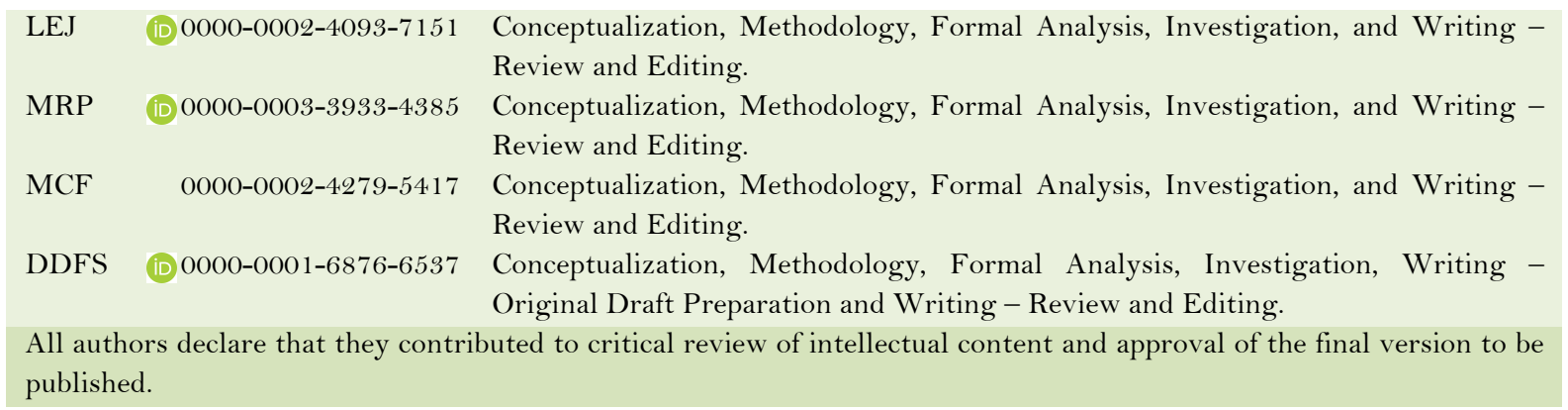

\section{Financial Support}

None.

\section{Conflict of Interest}

The authors declare no conflicts of interest.

\section{References}

[1] American Academy of Pediatric Dentistry (AAPD). Policy on Early Childhood Caries (ECC): Classifications, Consequences, and Preventive Strategies. Reference Manual 206/2017; 38(6):52-54.

[2] Graves CE, Berkowitz RJ, Proskin HM, Chase I, Weinstein P, Billings R. Clinical outcomes for early childhood caries: influence of aggressive dental surgery. J Dent Child 2004; 71(2):114-7.

[3] Brasil. Ministério da Saúde. Projeto SB Brasil 2003: Condições de Saúde Bucal da População Brasileira $2002-2003$. Brasil. 2004. [In Portuguese]

[4] Brasil. Ministério da Saúde. Secretaria de Atenção à Saúde. Secretaria de Vigilância em Saúde. Departamento de Atenção Básica. Coordenação Geral de Saúde Bucal. SB Brasil 2010 - Resultados Principais; Brasília, 2011. [In Portuguese]

[5] Narvai PC, Antunes JLF, Moysés SJ, Frazão P, Peres MA, Peres KG, de Souza MLR, Roncalli AG. Scientific validity of epidemiological knowledge based on data from the Brazilian Oral Health Survey (SB Brazil 2003. Cad Saúde Pública 2010; 26(4):647-70. https://doi.org/10.1590/s0102-311x2010000400002

[6] Sheiham A, Alexander D, Cohen L, Marinho V, Moysés S, Petersen PE, et al. Global oral health inequalities: task group - implementation and delivery of oral health strategies. Adv Dent Res 2011; 23(2):259-67. https://doi.org/10.1177/0022034511402084

[7] International Association of Paediatric Dentistry. Early Childhood Caries: IAPD Bangkok Declaration. Int J Paediatr Dent 2019; 29(3):384-6. https://doi.org/10.1111/ipd.12490

[8] Roncalli AG, Silva NN, Nascimento AC, Freitas CHSM, Casotti E, Peres KG, et al. Relevant methodological issues from the SBBrasil 2010 Project for national health surveys. Cad. Saúde Pública 2012; 28(Suppl):40-57. https://doi.org/10.1590/So102-311X2012001300006

[9] Listl S, Galloway J, Mossey PA, Marcenes W. Global economic impact of dental diseases. J Dent Res 2015; 94(10):1355-61. https://doi.org/10.1177/0022034515602879

[10] Kassebaum NJ, Bernabé E, Dahiya M, Bhandari B, Murray CJ, Marcenes W. Global burden of untreated caries: a systematic review and meta regression. J Dent Res 2015; 94(5):650-58. https://doi.org/10.1177/0022034515573272

[11] Brasil. Ministério da Saúde. Secretaria de Atenção à Saúde. Departamento de Atenção Básica. Saúde Bucal. Brasília (Cadernos de Atenção Básica, n. 17) (Série A. Normas e Manuais Técnicos); 2006. [In Portuguese] 
[12] Brasil. Ministério da Saúde. Grupo Hospitalar Conceição. Gerência de Saúde Comunitária. A saúde bucal da criança de o a 12 anos. Atenção à saúde da criança de 0 a 12 anos. Porto Alegre: Hospital Nossa Senhora da Conceição, 2008. p.111-118. [In Portuguese]

[13] Brasil. Ministério da Saúde. Grupo Hospitalar Conceição. Gerência de Saúde Comunitária. A saúde bucal da criança de o a 12 anos. Atenção à saúde da criança de 0 a 12 anos. $2^{\text {nd }}$. ed. Porto Alegre: Hospital Nossa Senhora da Conceição, 2014. p.133-148. [In Portuguese]

[14] Gradella CMF, Oliveira LB, Ardenghi TM, Bonecker M. Caries Epidemiology in children aged 5-59 months-old in the city of Macapá, State of Amapá, Brazil. RGO 2007; 55(4):329-34.

[15] Piovesan C, Moro BLP, Lara JS, Ardenghi TM, Guedes RS, Haddad AE, et al. Laboratorial training ofexaminers for using a visual caries detection system in epidemiologicalsurveys. BMC Oral Health 2013; 13:49. https://doi.org/10.1186/1472-6831-13-49

[16] Cericato GO, Garbin D, Fernandes APS. Surgeon-dentist insertion in the Family Health Program: a critical revision on the actions and evaluation methods of the Oral Health Team. RFO 2007; 12(3):18-23.

[17] Pauleto ARC, Pereira MLT, Cyrino EG. Oral health: a critical review about educative programmes for students. Ciênc Saúde Coletiva 2004; 9(1):121-30. https://doi.org/10.1590/S1413-81232004000100012

[18] Cascaes AM, Bieleman RM, Clark VL, Barros AJD. Effectivenessofmotivationalinterviewingatimproving oral health: a systematic review. Rev Saúde Pública 2014; 48(1):142-53. https://doi.org/10.1590/s0034-8910.2014048004616

[19] Gao X, Lo EC, Kot SC, Chan KC. Motivational interviewing in improving oral health: a systematic review of randomized controlled trials. J Periodontol 2014; 85(3):426-37. https://doi.org/10.1902/jop.2013.130205

[20] Colvara BC, Faustino-Silva DD, Meyer E, Hugo FN, Hilgert JB, Celeste RK. Motivational interviewing in preventing early childhood caries in primary healthcare: a community-based randomized cluster trial. J Pediatr 2018; 201(10):190-5. https://doi.org/1016/j.jpeds.2018.05.016

[21] Moynihan P, Tanner LM, Holmes RD, Hillier-Brown F, Mashayekhi A, Kelly SAM, et al. Systematic review of evidence pertaining to factors that modify risk of early childhood caries. JDR Clin Trans Res. 2019 Jul;4(3):202-216. https://doi.org/10.1177/2380084418824262

[22] Ardenghi TM, Piovesan C, Antunes JLF. Inequalities in untreated dental caries prevalence in preschool children in Brazil. Rev Saúde Pública 2013; 47(Suppl3):129-37. https://doi.org/10.1590/So034-8910.2013047004352

[23] Catani DB, Meirelles MPMR, Sousa MLR. Dental caries and social determinants of health in scholars at Piracicaba SP. Rev Odontol UNESP 2010; 39(6):344-50.

[24] Noro LRA, Roncalli AG, Mendes Júnior FIR, Lima KC. Use of dental care by children and associated factors in Sobral, Ceará State, Brazil. Cad Saúde Pública 2008; 24(7):1509-16.

https://doi.org/10.1590/So102-311X2008000700005

[25] Tinanoff N, Baez RJ, Diaz Guillory C, Donly KJ, Feldens CA, McGrath C, et al. Early childhood caries epidemiology, aetiology, risk assessment, societal burden, management, education, and policy: Global perspective. Int J Paediatr Dent 2019; 29(3):238-48. https://doi.org/10.1111/ipd.12484

[26] Kirthiga M, Murugan M, Saikia A, Kirubakaran R. Risk factors for early childhood caries: a systematic review and meta-analysis of case control and cohort studies. Pediatr Dent 2019; 41(2):95-112.

[27] Machado APS, Brunetto S, Faustino-Silva DD. Report of joint service experience dentistry and nutrition for children 0-36 months in a basic health unit in the city of Porto Alegre-RS. Rev Fac Odontol Porto Alegre 2011; 52(1/3):49-55. https://doi.org/10.22456/2177-0018.27537

[28] Garbin CAS, Saliba NA, Moimaz SAS, Santos KT. O papel das universidades na formação de profissionais na área da Saúde. Rev ABENO 2006; 6(1):6-10. [In Portuguese]

[29] Pereira DQ, Pereira JCM, Assis MMA. The odontological practice in the Basic Health Units in Feira de Santana, Bahia, in the health municipalization process: individual, autonomous, curative and technical activities. Ciênc Saúde Coletiva 2003; 8(2):599-609. https://doi.org/10.1590/S1413-81232003000200020

[30] Reis ML, Luvison IR, Faustino-Silva DD. Oral health knowledge, attitudes, and practices of doctors and nurses in the PHC of children. RFO UPF 2015; 20(2):164-71. 